\title{
Performance, escritura y oralidad en la socialización profesional de los abogados argentinos
}

\section{Fernando Fischman}

Universidad de Buenos Aires-CONICET

E-mail: ffischman@sinectis.com.ar 


\section{Resumen}

Este artículo tiene como enfoque la vinculación entre oralidad y escritura efectuada en las situaciones de performance que se generan en el ámbito de las clases de Derecho, particularmente la clase de Práctica Profesional de la última fase del proceso de formación de los abogados en la Universidad de Buenos Aires. La noción de performance formulada por Richard Bauman pone el acento en la dimensión estética de los procesos comunicativos y por eso es bases de esta investigación. Focaliza así en una de las dinámicas que tienen lugar en las performances áulicas mencionadas: los procesos de contextualización por medio de los cuales se enseña a contextualizar, es decir, los recursos pedagógicos por medio de los cuales se enseña a extraer fragmentos de discursos de entornos anteriores de producción y a situarlos en nuevos contextos discursivos. ${ }^{1}$

Palabras-clave: Performance. Pedagogía jurídica. Contextualización. Géneros Discursivos.
Abstract

This essay is centered on a concern for the linkage between orality and writing in situations of performance in the realm of classes taught in Law school, particularly in the discipline of Professional Practice, ministered in the last semester of Law School at the University of Buenos Aires. I deploy the notion of performance developed by Richard Bauman, which emphasizes the aesthetic dimension of the communicative processes. I thus focus on one of the teaching mechanisms that takes place in the class performances: the process of contextualization through which contextualization is itself taught: that is, the pedagogical resources deployed to teach how to extract discursive fragments from previous contexts of production and resituate them in new discursive contexts.

Keywords: Performance. Juridic Pedagogy. Contextualization. Discursive Genres.

ILHA 
$\mathrm{E}$ l concepto de performance permite aproximarse a innumerables manifestaciones socioculturales como los rituales, el teatro, las fiestas, y analizar las significaciones creadas por el hacer, por el poner en escena, por el desplegar creativo en público. Pero no es sólo en la investigación de estas expresiones de la dinámica colectiva aquí destacadas donde la noción de performance resulta sumamente productiva, sino que también hay otras instancias donde la performance como modo comunicativo se encuentra extendida. En todas las interacciones comunicativas, tanto las excepcionales como las cotidianas, puede producirse una activación de este modo de performance para destacar una situación de enunciación particular, para hacerla palpable y así subrayar públicamente lo que ahí está ocurriendo. ${ }^{2}$

La noción de performance con la que desarrollo la investigación y cuyos alcances presento en este artículo es la formulada por Richard Bauman en una serie de trabajos iniciados ya en la década de 1970 que aborda desde la cuestión del arte verbal y la narrativa (Bauman, 1977; 1986) hasta un conjunto de planteos posteriores en relación al concepto de contextualización e intertextualidad (Bauman y Briggs, 1990; Briggs y Bauman, 1996). En ellos Bauman complejiza la su idea de performance y pone la mirada en la multiplicidad de mediaciones presentes en los intercambios comunicativos y en la forma en que a través de estas se constituyen sujetos y se socializa el conocimiento. Su idea de performance precisa las características de los fenómenos expresivos que ésta puede abarcar y da claves para encarar su análisis. Bauman define performance como un "modo de comunicación marcado estéticamente, y destacado, especialmen- 
te encuadrado y puesto en exhibición ante una audiencia para su evaluación" (1992, p. 41). Delimita así a la performance como un espacio donde las manifestaciones expresivas que provocan un extrañamiento respecto de lo habitual o de lo esperado, se elaboran intersubjetivamente en una dinámica dialógica. Asimismo, plantea dos sentidos principales del concepto de performance. Uno, como modo artificioso de comunicación, en el cual la manifestación artística individual adquiere una importancia primordial en contextos situacionales particulares, por ejemplo, el enunciado de un proverbio o la narración de un relato en el marco de una interacción comunicativa habitual. El otro, centrado en acontecimientos públicos como la "performance cultural" delineada por Milton Singer (1972), manifestada en celebraciones, en ferias, en el teatro, situaciones donde por medio de la exaltación de la experiencia se exponen, se someten a escrutinio, se discuten los valores vigentes en un colectivo social (Bauman, 1994).

Todos los entornos educativos son espacios ricos en situaciones de performance en las cuales adquiere primordial importancia uno de los elementos constitutivos de la definición de performance de Bauman, la evaluación (1992). ${ }^{3}$ Ello porque principalmente el docente, y también los estudiantes, tienen que demostrar su saber, su habilidad, su destreza, en el contexto de intercambios comunicativos situados. En las instituciones educativas los roles están pautados y en el marco del aula hay habitualmente el docente como performer principal y hay alumnos. El docente tiene la autoridad porque posee los conocimientos y es quien en última instancia evaluará a los estudiantes, pero él también está siendo evaluado permanentemente por su audiencia por las competencias que demuestra y por la pericia con la que da la clase. Las instancias áulicas son performáticas en los dos sentidos anteriormente planteados. Eso es así ya que son espacios sociales delimitados, reconocidos en su singularidad con respecto a otros espacios, donde se exalta la experiencia por medio de la poética de la comunicación. ${ }^{4}$ Además, hay tipos específicos de clase cuyo fundamento es la situación de performance. En éstas, se acentúa la clave que pone a todos los participantes alternativamente en escena. 
Ese es el caso de la clase de Práctica Profesional en la última fase del proceso de formación de los abogados en la Universidad de Buenos Aires. Las situaciones de performance que tienen lugar en las clases de Práctica Profesional del Patrocinio Jurídico Gratuito del Palacio de Tribunales, con sus particularidades, son primordiales para la transmisión del conocimiento a los futuros abogados y también, se puede argumentar, aunque excede los objetivos de este trabajo, para la reproducción del sistema judicial argentino. En este artículo pongo el foco en una de las dinámicas que tienen lugar en las performances áulicas mencionadas: los procesos de contextualización por medio de los cuales - valga la reiteración del término - se enseña a contextualizar, es decir, los recursos pedagógicos por medio de los cuales se enseña a extraer fragmentos de discursos de entornos anteriores de producción y a situarlos en nuevos contextos discursivos. Específicamente, me centro en la vinculación entre oralidad y escritura efectuada por medio de los mencionados procesos en las situaciones de performance que se generan en el ámbito de dichas clases.

\section{La performance de la clase de Derecho como espacio de convergencia: la escritura, la oralidad, el sistema judicial argentino y la pedagogía jurídica}

En base a las características del sistema judicial argentino, la pedagogía jurídica, en particular la clase de Práctica Profesional, ofrece desafiantes problemáticas para pensar la relación entre performance, escritura y oralidad porque involucra la enseñanza de los procesos judiciales de producción discursiva a través de las prácticas de la descontextualización y recontextualización (Bauman y Briggs, 1990).

En el caso de Argentina, el sistema judicial está constituido en base a la escritura. La justicia argentina se administra por escrito. Los procesos se llevan en expedientes escritos. Incluso las audiencias orales se transcriben, se pasan al papel. Una de las frases más comunes en el ambiente judicial es que "lo que no está en el expediente no existe". Ello significa que aunque algún enunciado haya sido formulado inicialmente de otras maneras - en forma oral o como un 
documento escrito de distinta índole - si no fue incorporado al formato legal correspondiente por medio de una transposición a un tipo específico de escritura, no tiene entidad.

Una de las tareas a cual se aboca la enseñanza del Derecho en la Universidad de Buenos Aires es la instrucción en una serie de estrategias para reconducir discurso de distinto orden documentación, intercambios conversacionales - hacia el escrito judicial. La carrera de abogacía se desarrolla en tres etapas: un Ciclo Básico Común (CBC), un Ciclo Profesional Común (CPC) y un Ciclo Profesional Orientado (CPO). ${ }^{5}$ El plan de estudios prevé que antes de recibirse de abogados los estudiantes adquieran experiencia en la tramitación de casos. Con ese fin, hacia el final del último ciclo, los estudiantes deben cursar un año de la asignatura Práctica Profesional. Ello se cumple en el Patrocinio Jurídico Gratuito ubicado en el Palacio de Tribunales. El Patrocinio Jurídico atiende a gente que no posee recursos económicos para pagar un abogado, a quienes se denomina "consultantes".

El cursado de Práctica Profesional consiste en la asistencia de los estudiantes una vez por semana a la Facultad de Derecho donde reciben instrucción teórica y dos veces por semana al Patrocinio Jurídico Gratuito. Los estudiantes tramitan los casos guiados por un equipo conformado por profesores y ayudantes, todos abogados matriculados, que son quienes también "firman" las presentaciones. "Llevar" los casos implica, para los estudiantes atender a los consultantes cuando asisten al patrocinio y dejar constancia en el expediente testigo de su asistencia y la fecha próxima de citación. Asimismo, estudian las cuestiones de fondo y de forma de cada caso particular, redactan las piezas procesales, se las dan a corregir al profesor titular o sus ayudantes y una vez corregidas y firmadas los llevan a los juzgados. También realizan la recorrida de tribunales y anotan los avances en una hoja de ruta dejando constancia de la fecha que fueron a ver el expediente. También asisten a las audiencias y a todas las actividades que el caso pueda demandar, siempre acompañados u orientados por los docentes. 
Si bien las instancias principales de comunicación entre docentes y estudiantes se dan en el Patrocinio Jurídico, aparte de ellas, la interacción entre éstos se continúa por distintos medios por fuera del ámbito institucional: se comunican telefónicamente, se mandan correos electrónicos, se encuentran fuera de los horarios de clase, asisten juntos a las audiencias. Este contacto fluido tiene lugar debido a la índole específica de Práctica Profesional. El tratarse de "casos reales" implica un número de situaciones que deben ser resueltas por fuera de los horarios de clase establecidos, y la interacción entre docentes y estudiantes excede el plano del espacio y los tiempos institucionales. No obstante, estas interacciones pueden pensarse como complementarias a la performance de la clase. En ella, el diálogo entre un docente y un estudiante no tiene como performer principal al primero y como audiencia única al segundo, sino que el destinatario del mismo es la clase en su conjunto.

Cada comisión de Práctica Profesional tiene su modalidad específica de organización aunque en líneas generales, en todas las comisiones se mantiene la división entre la instancia de diálogo entre docentes y estudiantes y la de intercambio entre docentes, estudiantes y consultantes. En algunas está formalmente pautado el ingreso de los consultantes, en otras éste es más espontáneo. Las comisiones se reúnen durante dos horas en oficinas pequeñas donde se agolpan los estudiantes con los docentes y también se recibe a los consultantes.

En la primera hora, los docentes revisan los casos con los estudiantes. ${ }^{6}$ Éstos dan cuenta de los avances que realizaron, de las gestiones y trámites concluidos, de los llamados telefónicos que hicieron o recibieron de los abogados de la otra parte o de los propios consultantes. Ello da lugar a una gran expansión de la actividad narrativa. Por ejemplo, los alumnos relatan las situaciones que se le presentaron al llevar un escrito a un juzgado, o los llamados que recibieron de los consultantes relatándoles cosas que no se animaron a contar en la oficina.

En la segunda hora, los consultantes, que están sentados en una Sala de Espera ubicada a la entrada del Patrocinio, son autoriza- 
dos a ingresar a la oficina de a uno y se van diligenciando sus trámites. Y esta situación también genera un gran despliegue de performance. Cuando asiste a su reunión inicial el consultante es sometido a una entrevista por parte de un par de estudiantes, que son quienes van a "tomar el caso", bajo la supervisión de los docentes y la atención de los otros estudiantes, quienes también les pueden preguntar. En esa entrevista el consultante relata los acontecimientos que lo llevaron a buscar asistencia jurídica en el Patrocinio. En las sucesivas presentaciones en que los consultantes son citados o vienen por su cuenta, éstos exponen lo que ha ido ocurriendo y dialogan sobre su caso con los estudiantes que lo están llevando, en presencia también de los otros estudiantes y de los docentes.

La clase de Práctica Profesional en el Patrocinio Jurídico es una instancia de interacción comunicativa donde se procura forjar el saber hacer del abogado frente a situaciones concretas, a partir de conocimientos teóricos previos. Debido a que todos los participantes se ven obligados a exhibir destrezas ante una audiencia que se va alternando, es una situación de performance por excelencia. ${ }^{7}$ Se aproxima en buena medida a aquello que Bauman denomina "performance mediacional". Bauman afirma en sus trabajos sobre las rutinas mediacionales $(2000,2004 b)$ que la estructura de las situaciones comunicativas puede ser más compleja que la de la díada emisor/receptor. En ellas se manifiestan más roles y también se alternan. ${ }^{8}$ Éstas consisten en rutinas de habla organizadas a través de la réplica que hace un mediador de por lo menos un enunciado desde una fuente original hacia un destinatario, siendo el mensaje replicado enmarcado y entendido por los participantes de la interacción comunicativa como una reiteración de dicha fuente original. ${ }^{9}$

¿Y cómo se manifiestan las performances mediacionales en estas clases?

Los consultantes se ven obligados a desarrollar una retórica orientada a convencer de la justicia de su reclamo, frente a docentes y estudiantes, ya que desde la entrevista inicial, cada vez que asisten deben hablar ante la mirada y la escucha atenta de todos, que también les formulan preguntas y ponen en entredicho sus afirmaciones. 
Los docentes despliegan sus conocimientos, que se espera que sean precisos y se ajusten a lo que los casos que se están tratando reclaman, frente a los estudiantes y a los consultantes. No se trata únicamente de mostrar un conocimiento abstracto del Derecho, sino de dar respuesta a situaciones concretas. Se espera que ellos sepan qué curso de acción tomar ante cada situación y que lo enuncien de un modo que resulte claro y didáctico para los alumnos.

Los estudiantes tienen que exhibir sus conocimientos y sus logros frente a los docentes, a los otros estudiantes, y a los consultantes. Por lo tanto, las clases de Práctica Profesional en el Patrocinio Jurídico se desarrollan con un gran despliegue performático en sus dos etapas que se convierten, en virtud de los participantes involucrados, en dos escenarios diferenciados. En uno y en otro cambia la composición de la audiencia, aparecen nuevos actores y algunos de ellos se ven obligados a cambiar drásticamente de rol.

Cuando los consultantes no están los alumnos de la carrera pueden ser objeto de interrogación por parte de los docentes con respecto a distintas cuestiones, tanto teóricas como de procedimiento. Asimismo suelen solicitarles que narren los relatos hechos por los consultantes en otro momento, de modo de poder armar conjuntamente el caso. También en esta situación los estudiantes pueden ser reprendidos si no cumplieren con lo que deben realizar o si se equivocaren al hacerlo. En estos diálogos que tienen lugar como performance los roles de performer principal y de audiencia van variando conforme avanza la clase: el docente pasa de ser la audiencia de los consultantes a ser un performer principal, el consultante que en un momento determinado es un performer principal, en cierta instancia es invisibilizado. Cuando los consultantes están presentes, aún cuando éstos saben que se trata de estudiantes, los alumnos están obligados a asumir su rol profesional y los docentes no pueden desautorizarlos públicamente. Ello no obsta para que si cometen un error frente a los consultantes, o les hacen un comentario inconveniente, los docentes no marquen también públicamente los errores por medios que sólo una parte de la audiencia - los estudiantes puede decodificar: por ejemplo, a través de gestos, miradas, cambios en la entonación. 
El estudiante que asume el rol de performer principal en su diálogo con el docente es simultáneamente audiencia de más de un performer en una misma situación.

La modalidad específica de performance tipificada en este contexto la hemos denominado "tramitar y hablar del trámite" (Fischman, Goncalves Charneca e Imas, 2009). Ésta consiste en una reflexión acerca de una práctica realizada o a llevar a cabo que se despliega públicamente. Involucra un diálogo entre docentes y estudiantes en el cual se invocan conocimientos teóricos y éstos se vinculan con los quehaceres puntuales necesarios para gestionar cada trámite. Dicho diálogo es una instancia de elaboración intersubjetiva de conocimiento.

\section{El diálogo docente-estudiante como género pedagógico emergente de Práctica Profesional}

En la enseñanza del Derecho se plantea entonces una intrincada relación entre oralidad y escritura. En las situaciones de performance de las clases, la oralidad, que es el modo comunicativo predominante, se pone al servicio de enseñar a subsumir la oralidad en la escritura.

Por lo tanto, en relación a la enseñanza del Derecho, la performance es un espacio de intermediación en el cual, a través de la expresión oral realizada en el aula, se inicia a los estudiantes en la producción de textos escritos a partir de manifestaciones escritas y orales previas. Es decir, se enseña la producción de textos jurídicos que son inherentemente interdiscursivos en tanto provienen de múltiples contextos de enunciación.

¿Cómo se lleva a cabo esta enseñanza? Los docentes de Derecho elaboran la situación de oralidad en la que dictan su clase partiendo principalmente desde el registro escrito. Sus materiales básicos - las leyes, los códigos, la jurisprudencia, la doctrina - se encuentran escritos. No obstante, también hay relevantes instancias externas a las clases donde la oralidad ocupa un lugar principal, como las reuniones de cátedra o las conversaciones con los colegas. Todas estas instancias orales se desarrollan por fuera de la situación de clase. La 
circunstancia pedagógica de enseñar a ejercer la abogacía implica la utilización del código oral en situaciones de performance para instruir en los procedimientos profesionales. Uno de los más importantes de éstos procedimientos es la redacción de los escritos necesarios para desempeñarse en el sistema. Esto es, enseñarles a los estudiantes a redactar los escritos judiciales con las palabras precisas ya que en esta instancia se realiza la efectiva incorporación de las prácticas jurídicas. Entre los procedimientos que llevan a cabo los docentes, ocupa un lugar destacado la instrucción en el uso "apropiado" del lenguaje "apropiado" en el contexto "apropiado". Esto significa enseñar a verbalizar por escrito los enunciados correctos en su contexto correcto. Implica entonces enseñar a transcribir a la escritura aquello que se enunció oralmente, pero no a una escritura cualquiera sino a la redacción de un escrito judicial. Ello ocurre por medio de diálogos puntuales que se despliegan ante toda la clase.

Los estudios etnográficos de las Facultades de Derecho en los EE.UU. de Elizabeth Mertz $(1996,1998)$ dan cuenta de cómo el acto de traducción en lenguaje legal es uno en el cual la regimentación lingüística y social se unen. Pero tanto el sistema judicial argentino como la formación profesional en Derecho tienen características muy distintas en Argentina con respecto a los EE.UU. Si bien todos los procesos de recontextualización discursiva en la arena judicial tienen perfiles similares, hay rasgos que en uno y en otro son disímiles. También la estructura curricular es distinta. En EE.UU. la educación en Derecho tiene lugar en una escuela profesional que se realiza al nivel de posgrado con una duración de aproximadamente dos años. En la Argentina la carrera de abogacía es de grado, esta organizada en un plan de estudios realizable en aproximadamente cinco años.

Mertz se centra en la práctica del método de enseñanza más extendido en las Facultades de Derecho de los EE.UU., el Método Socrático, como la instancia donde los estudiantes son adiestrados en la recontextualización discursiva. En la Universidad de Buenos Aires predomina la clase magistral donde el docente expone sus conocimientos ante los alumnos, por lo general con bastante poca participación de éstos. Esta situación cambia drásticamente en el 
cursado de Práctica Profesional. Que afirme que a lo largo de la carrera de abogacía "predomina" un modo de dar clase no significa que éste sea el único. Por cierto, los docentes de las diferentes cátedras, con los matices que los caracterizan, buscan formas alternativas a la clase magistral.

A continuación presento un segmento de una interacción en el ámbito del Patrocinio Jurídico Gratuito, ubicado en el octavo piso del Palacio de Tribunales, en una de las comisiones donde se llevan a cabo las actividades didácticas que son, simultáneamente como ya fue dicho, profesionales.

La observación que es la base del registro aquí presentado fue realizada en el mes de noviembre de 2008. La situación tiene lugar en la primera etapa de la clase, antes que entren los consultantes.

La profesora va interrogando a los estudiantes respecto del caso que están llevando y cada uno le cuenta las novedades pertinentes. La audiencia está constituida por el resto de los estudiantes que se encuentra en la oficina. La docente corrige terminología utilizada en los escritos y sugiere los pasos a seguir en cada caso.

Transcribo el registro de campo de una interacción entre la profesora, un ayudante y una estudiante: ${ }^{10}$

El ayudante le lee a la profesora la declaratoria de herederos. ${ }^{11}$ Ven un error de tipeo. La alumna pregunta si ella lo tiene que copiar igual. La profesora le dice que no. (Se refieren a un error de tipeo del Juzgado en la Declaratoria; como la alumna debe transcribir el texto para confeccionar el Testimonio, pregunta si la transcripción debe ser exacta, incluyendo el error del Juzgado. La profesora le contesta que no, que este error puede corregirlo para el Testimonio ${ }^{12}$ ).

La profesora, el ayudante y la alumna interactúan frente a la clase en torno a la producción de un texto escrito. Se trata de la "Declaratoria de herederos", resolución judicial por la cual quedan establecidos los herederos de una persona.

A los fines del análisis de esta situación particular la "Declaratoria de herederos" en cuestión puede ser definida como el "texto original" ya que es aquel a partir del cual se dirimirá la posibilidad de un 
cambio a través de esta performance específica. También es un "texto original" porque llega en ese formato de resolución judicial desde el Juzgado, aunque hubo otras instancias previas, tanto orales como escritas por medio de las cuales se alcanzó el formato de "Declaratoria". En esta etapa del proceso judicial, este texto original será reelaborado para convertirse en otro texto escrito, el "Testimonio". La realización del "Testimonio" involucra un proceso de descontextualización y recontextualización que realiza el abogado, ya que éste debe hacer una trascripción de la resolución judicial, pero no en su totalidad, sino de la parte resolutiva. Para que este texto tenga validez, tiene que "dejarlo a confronte" en el juzgado, es decir darlo para que se vea si lo que se copió se ajusta a la resolución judicial o no, y esperar que secretario del Juzgado lo firme para autorizar su validez. Es decir, el texto es, en principio, fácilmente entextualizable, pero debe ajustarse a ciertas normas. El Testimonio entonces es una producción autorial del abogado que se realiza dentro de ciertos límites: aquellos provistos por el texto de base, por los requerimientos de los contenidos formales que éste debe tener para ser válido, propuestos por el sistema judicial, y por el control del Juzgado.

La performance por medio de la cual se enseña a transformar el texto original en esta clase se inicia cuando el ayudante le lee a la profesora la resolución judicial en voz alta. Este primer pasaje a la oralidad permite notar un error de tipiado en el texto, error que procede del juzgado donde se expidió la declaratoria.

La alumna - que deberá cumplir el rol de transcribir el texto de la declaratoria para confeccionar el "Testimonio", actividad que le cabría hacer también si fuese abogada - pregunta si su trascripción debe incluir el error, a lo que la profesora le contesta que ese error, que proviene del Juzgado, puede corregirlo cuando redacte el "Testimonio". Es decir que en su redacción puede realizar una corrección al texto original sin que ello tenga una consecuencia en los efectos de su escrito. En este caso, la transposición de un texto a otro permite la modificación del original. La brecha intertextual (Briggs y Bauman op.cit.) admitida entre uno y otro documento permite la corrección de errores de tipiado del original y por esa razón, la docente habilita a la alumna a efectuar la corrección. 
Como se observa en el siguiente diálogo entre ayudante ${ }^{13} y$ alumno ocurrido en otra comisión de Práctica Profesional en una circunstancia en la que también se está trabajando sobre la realización de un Testimonio, las posibilidades de alteración del texto original, son muy bajas. El docente organiza su discurso de modo de transmitir fehacientemente esta noción. ${ }^{14}$

Ayudante: (Se dirige al grupo y les dice respecto de una causa) Acá tienen que hacer el testimonio [...] ¿Tiene alguna particularidad el testimonio? ¿Qué tiene que tener?

Alumno: La transcripción íntegra de la parte resolutiva de la sentencia de divorcio.

Ayudante: ¿Qué particularidades tiene el Testimonio? ¿Lo volcamos así como lo sacamos de Internet? Recuerden, números en letras y que no tiene que haber abreviaturas. Si dice fs. ponen fojas. Una vez que transcribieron la parte resolutiva en letras y sin abreviaturas ponen "Lo testimoniado es copia fiel de su original de fojas..." [...] Además ¿Hay que dejar constancia de algo? Hay que dejar constancia de que la sentencia de divorcio se encuentra firme e inscripta en el Registro Civil. Con eso acredita en cualquier lado su situación real.

En esta instancia, el docente avanza los contenidos de su clase por medio de preguntas. Interactúa con los estudiantes formulando distintos tipo de interrogaciones. Así, inquiere acerca de las características del documento denominado "Testimonio" (¿Tiene alguna particularidad el Testimonio? ¿Qué tiene que tener?). Uno de los alumnos da una respuesta conceptual. El docente reformula su interrogación porque está apuntando hacia las cuestiones formales y hace una pregunta general respecto a las "particularidades" (¿Qué particularidades tiene el Testimonio?) e inmediatamente otra (¿Lo volcamos así como lo sacamos de Internet?) acerca del formato. Y es el docente mismo quien provee la respuesta que estaba buscando. Afirma que hay que hacer una transposición formal respecto del modo en que los fallos son publicados en Internet. Los números deben escribirse en letras y no se puede poner abreviaturas. Y da ejemplos. Luego recita la fórmula con la que se debe finalizar el Testimonio y que debe ser puesta sin cambios. Reafirma así el carácter de texto fijo, cerrado, del escrito. ${ }^{15}$ 
En el siguiente segmento, también procedente de la parte de una clase en la que no hay consultantes presentes, es posible determinar cómo se va articulando verbalmente en el diálogo entre docente y estudiantes la regimentación lingüística que determina las características formales de un escrito jurídico.

Profesora: ¿Quién lo lleva a Gómez? (Lee el escrito realizado por alumnos) luego de convivir con... hijas... y a raíz de... ¿a raíz o como consecuencia? Hechos ${ }^{16}$ : si vive en una casa que ya compartimos o no, ¿en qué hace a los hechos? Mi ex concubino no; el padre de mis hijas...te había dicho que no relates si vino, no vino, dijo o no dijo. Porque son puntos que traen conflicto. Y yo ya llegué a un acuerdo. El objeto es que se homologue.

Este fragmento se inicia cuando la profesora se dirige a su audiencia de estudiantes y pregunta por un caso particular. Los casos se "llevan" y se denominan de acuerdo al nombre del consultante. Luego realiza su pasaje de la escritura a la oralidad cuando comienza a leer el escrito preparado por los alumnos. Lo va leyendo en voz baja y levanta la voz cuando quiere aclarar o corregir algo. La primera corrección es una cuestión lexical que no tiene incidencia sobre la validez legal del escrito. Lee primero la frase "a raíz de" y la repite dando una alternativa por medio de una pregunta (¿a raíz o como consecuencia?). En la pregunta está contenida la respuesta ya que está sugiriendo la forma en que debe ser redactada la oración. La redacción tuvo una falta terminológica que no invalida el documento pero la marcación de la profesora se propone corregir lo que los docentes perciben como una falta de claridad en la redacción por parte de los estudiantes. ${ }^{17}$

Luego lee en voz alta el subtítulo formal del escrito "Hechos" en el cual se deben consignar las cuestiones que son relevantes para la presentación. Aquí realiza una serie de correcciones de distinto orden:

1. Cuestiona la relevancia de una de las frases como pertinente para los "hechos" (si vive en una casa que ya compartimos o no, ¿en qué hace a los hechos?)

\section{ILHA}

volume 11 - número 1 
2. Corrige terminología (Mi ex concubino no; el padre de mis hijas)

3. Objeta determinadas frases del escrito que narran situaciones sucedidas ("si vino o no vino, dijo o no dijo") argumentando que estas manifestaciones generan conflictos una vez que ya se logró un acuerdo. Trata de señalar así que el escrito no debe poseer marcas discursivas de desacuerdos que den lugar a interpretaciones o a nuevas preguntas por parte del juez o de la otra parte cuando ya se ha llegado a un acuerdo. Las discusiones anteriores deben quedar por fuera del escrito. Es decir, todos los enunciados previos, que incluyen los relatos de los sucedidos no son necesarios cuando se llegó a un acuerdo. Señala así que los escritos judiciales se redactan a través de un proceso de selección de acontecimientos. Esa es una habilidad a ser desarrollada por los abogados.

Y luego se dirige a su audiencia conformada tanto por los alumnos que redactaron el escrito como por los otros estudiantes afirmando que el objetivo es la homologación - la validación que hace un juez de un acuerdo entre partes, por lo cual es inaceptable la incorporación al escrito de narrativas sobre cuestiones ya dirimidas.

Los segmentos de las clases aquí presentados muestran formas en que los diálogos en performance son utilizados en un espacio áulico para enseñar a regimentar los textos. En los escritos judiciales los requisitos de forma son indispensables y los sentidos de los términos deben limitarse para no dar lugar a interpretaciones erróneas. Por lo tanto, enseñar a redactar los escritos implicar instruir para la configuración formal y semántica de los textos. La oralidad aquí juega un papel fundamental. Se trata de una oralidad tendiente a educar en la conformación de textos escritos. Este conocimiento es necesario como parte de la adquisición de las aptitudes indispensables para desempeñarse como abogado. Los diálogos en performance en las clases de Práctica Profesional enseñan a calibrar la brecha intertextual entre discursos de distinto orden: los escritos que deben elaborar los abogados y los discursos de base a partir de los cuales los producen. Así, los "Testimonios", que son extraídos de resoluciones judiciales tienen que acercarse al original a un punto tal que su similitud con 
el original debe ser constatada y refrendada por el Juzgado. Por otra parte, si se trata de presentar o responder una demanda, los dichos de los consultantes son los que se reconducen, en articulación con la prueba, al discurso jurídico por medio de operaciones de selección, adecuación, y adaptación al contexto. La dimensión emergente de la performance se manifiesta en el discurso oral de la clase, que surge de la interacción entre docentes y estudiantes. Ésta tiene como una de sus consecuencias la producción de un género dialógico oral que sirve para enseñar a confeccionar un texto escrito, al que también es posible caracterizar como "emergente". En este caso, la oralidad se utiliza para perfeccionar el texto escrito de modo que "sirva", es decir, que pueda atravesar exitosamente los caminos del sistema judicial.

\section{A modo de conclusión}

El discurso de la clase de Práctica Profesional de la Facultad de Derecho de la Universidad de Buenos Aires orienta a que el estudiante incorpore la utilización eficaz de un lenguaje especial en su contexto particular. Ello implica aprender a regimentar el discurso para elaborar los escritos incorporando las narrativas necesarias, en el formato conveniente, con la terminología "apropiada".

El manejo de una efectiva articulación entre oralidad y escritura es necesario toda vez que hay un sistema judicial donde éstas tienen un estatus diferenciado, en el cual la primera se subsume en la segunda. O quizás sea más correcto decir, debe ser subsumida en la escritura para tener una entidad legal. Esto implica que todo aquello que tiende a presentarse en forma oral, como los relatos de los demandantes y de los demandados ante sus abogados, las declaraciones de los testigos en los juzgados, los dichos de las partes en las audiencias, entre otras manifestaciones orales, todo debe ser volcado al canal escrito. Y no sólo eso, sino que la escritura debe respetar formas específicas para que los documentos tengan validez. Con el fin de enseñar la competencia en esta articulación entre oralidad y escritura la universidad, como institución educativa, desarrolla modos particulares de instrucción, es decir, recursos para 
instruir a los estudiantes en la profesión, una de cuyas competencias es el correcto uso de las formas escritas utilizadas en los procesos judiciales en conjunción con los procedimientos específicos.

Las situaciones de performance analizadas, surgidas entre muchas otras que tienen lugar durante el dictado de la asignatura Práctica Profesional en el Patrocinio Jurídico Gratuito de Tribunales, hacen a una modalidad de enseñanza particular. Esta tiene a la performance como eje. Se trata de una puesta en escena en la cual el estudiante ejerce un papel en dos dimensiones. Por un lado, es un alumno que debe desempeñarse apropiadamente para lograr su objetivo dentro de la institución educativa, esto es, aprobar la materia. Por otro, asume un rol profesional afín a la tarea que desempeñará cuando haya recibido su título.

Estas situaciones de performance ritualizadas en el trabajo cotidiano que se lleva a cabo en el Patrocinio Gratuito, a la par de instruir en la confección de los textos formales que se utilizan en el sistema judicial, van constituyendo géneros discursivos particulares que contribuyen a la socialización profesional. Esta socialización implica iniciar a los estudiantes en los procedimientos para llevar a cabo los trámites judiciales, pero principalmente supone enseñar a reconducir discursos de modo que resulten efectivos. Uno de los géneros más extendidos está constituido por los diálogos entre docente -que asume el rol de emisor - y un estudiante - el que redactó el escrito que se está discutiendo, o efectuó un trámite pertinente y que se constituye en el destinatario del enunciado del docente, aunque los otros estudiantes también participan como audiencia. Estos diálogos se configuran a través de preguntas, algunas de ellas de índole retórica, y de sus respuestas.

Elizabeth Mertz (1996) afirma que en el aula de la clase de Derecho los estudiantes son socializados en una nueva manera de hablar. En la Facultad de Derecho de la Universidad de Buenos Aires, los estudiantes son socializados en nuevas maneras de escribir. Convertirse en abogado significa aprender a elaborar los escritos judiciales y a conocer la lógica de su circulación. Ello no significa que no desarrollen un modo verbal oral de expresarse particular, ya 
que lo hacen y es ciertamente distintivo. Aunque resta encarar estudios específicos, existe una forma de habla de los abogados reconocida entre quienes se desempeñan en el ámbito judicial - que se podría hipotetizar es resultado de una proyección de la escritura jurídica que deja su impronta en su habla coloquial y los constituye en un grupo social diferenciado a partir de la dimensión estética de su oralidad. A su vez, como se mostró, dicha escritura se forja en buena medida en diálogos sostenidos oralmente. El efecto de las formas en que es necesario escribir sobre el modo en que posteriormente se habla, es un tema a seguir investigando. "Ser abogado" es conocer los procedimientos, la forma de redactar los escritos, pero también, hablar de un modo particular en los contextos pertinentes. Ese modo de hablar aparece como una vuelta a la esfera de la circulación oral del discurso jurídico escrito.

$\mathrm{Al}$ analizar las clases de la asignatura Práctica Profesional desde la perspectiva de la performance quedan en evidencia una serie de mediaciones dialógicas. En ellas se va armando la trama intersubjetiva de la enseñanza del Derecho. Las situaciones de performance en las que se regulan recíprocamente los modos discursivos del sistema educativo y del sistema jurídico resultan un elemento indispensable para la socialización profesional de expertos en Derecho cuya escritura y habla generarán efectos manifiestos en el sistema jurídico y a partir de éste, en múltiples dimensiones de la vida social.

\section{Notas}

1 Este artículo es una reelaboración de una versión preliminar presentada en el Colóquio "Antropologias em Performance", llevado a cabo en la Universidade Federal De Santa Catarina, los días 27, 28, 29 de mayo de 2009. Agradezco la invitación de las coordinadoras, Esther Jean Langdon, Luciana Hartmann y Vânia Zikán Cardoso, como las preguntas y comentarios recibidos en dicha ocasión que me permitieron avanzar en la reflexión a partir del trabajo leído en esa oportunidad.

2 Los estudios de la performance se han desarrollado desde ya más de tres décadas por autores como Victor Turner, Richard Schechner y Richard Bauman de acuerdo a concepciones que tienen puntos en común, pero también divergencias de enfoque. Esther Jean Langdon (2009) analiza extensamente estas diferentes aproximaciones a las cuales denomina "paradigmas analíticos" de la performance.

3 Este trabajo se inscribe en el Proyecto UBACyT D420 de la programación 2008-2010, denominado "La pedagogía jurídica en la Universidad de Buenos Aires: estudio

\section{ILHA}

volume 11 - número 1 
etnográfico de la enseñanza del Derecho a través del concepto de performance" en curso bajo mi dirección.

4 Por función poética me refiero a los planteos desarrollados por Roman Jakobson (1960) (¿cuál libro o artículo?) en relación a las funciones del lenguaje.

5 Según el Plan de Estudio de la Carrera de Abogacía aprobado en 2004.

6 Cada comisión tiene su modalidad específica de organización. La aquí presentada se corresponde con aquella con la que cuento con mayor número de registros. En líneas generales, en todas se mantiene la división entre la instancia de diálogo entre docentes y estudiantes y la de intercambio entre docentes, estudiantes y consultantes.

7 Como abordo anteriormente, las modalidades particulares de trabajo de cada comisión varían según el docente a cargo. En algunas sólo quienes llevarán el caso conocen los detalles del mismo. En otras éstos son compartidos por todos. Algunos docentes, cuando se retiran los consultantes, preguntan a toda la clase con la intención de que todos los estudiantes propongan alternativas para encarar el caso.

8 El estudio de Kwesi Yankah (1995) muestra esto de manera contundente.

9 Bamann $\left(2004^{\mathrm{a}}\right)$ tipifica una serie roles de las performances mediacionales (participante, emisor, autor, fuente, receptor, destinatario, oyente casual, objetivo, audiencia, mediador)

${ }^{10}$ El registro fue realizado por Verónica Imas por medio de anotaciones.

11 Declaratoria de herederos: Resolución judicial por la cual quedan establecidos los herederos de una persona.

12 Testimonio: Extracto de una resolución judicial. Se trata de un documento con la firma del secretario del Juzgado en el que consta la decisión tomada por juez.

13 Ayudante: denominación del cargo de auxiliar docente en la Universidad de Buenos Aires

${ }_{14}$ Registro realizado por Egle Gonçalves

15 Esta situación de reformulación de preguntas por parte del docente se asemeja a aquella notada por Mertz (1996) en las clases de Derecho en los EE.UU. Sin tratarse aquí del Método Socrático que ella analiza, la repregunta del profesor frente a la respuesta "incorrecta" del estudiante es similar.

16 El subtitulo "Hechos" se utiliza en el escrito de demanda y en el de contestación de demanda o reconvención que son los escritos principales que constan en un expediente. Los Códigos Procesales exigen que la demanda contenga los hechos en que se funda el reclamo.

17 Esta queja se reitera en muchos de los docentes entrevistados y apunta a la mala formación en general, en relación a cuestiones idiomáticas y de manejo del lenguaje por parte de todos los estudiantes.

\section{Referencias}

BAUMAN, R. Verbal Art as Performance. Prospect Heights, Il: Waveland Press, 1977.

. Story, Performance and Event. Contextual Studies of Oral Narrative.

Cambridge University Press, 1986.

ILHA

volume 11 - número 1 
. Performance. En Folklore, Cultural Performances and Popular

Entertainments. New York Oxford: Oxford University Press, 1992. p.41-49.

. "Estudios norteamericanos de folklore y transformación social: una perspectiva centrada en la actuación" En Serie de Folklore 10, Facultad de Filosofía y Letras, Universidad de Buenos Aires: 3-20. 1994 [1989]. (Original en Text and Performance Quarterly vol.9 N03 ).

. Actuación mediacional, tradicionalización y la "autoría" del discurso. En: Patrimonio Cultural y Comunicación. Nuevos Enfoques y Estrategias. Museo de Motivos Argentinos "José Hernández". 2000. p. 31-51.

. Introduction: Genre, Performance, and the Production of

Intertextuality. En $A$ World of Others' Words. Cross-Cultural Perspectives on Intertextuality. Blackwell Publishing. 2004a. p. 1-14.

. "Go, My Reciter, Recite My Words": Mediation, Tradition, Authority. En A World of Others 'Words. Cross-Cultural Perspectives on Intertextuality. Blackwell Publishing. 2004b. p. 128-158.

.; BRIGGS, Ch. "Poetics and and Performance as Critical Perspectives on Language and Social Life" Annual Review of Anthropology $19: 1990.59-88$.

BRIGGS, Ch.; BAUMAN, R. "Género, intertextualidad y poder social". Revista de Investigaciones Folklóricas 11: 1996 [1992]. 78-108.

FISCHMAN, F.; GONCALVES CHARNECA, E.; IMAS, V. “Tramitar y hablar del trámite. Particularidades de la clase de Práctica Profesional en la carrera de Derecho de la Universidad de Buenos Aires" Ponencia presentada en la $5^{\text {a Jornada sobre }}$ Material Didáctico y Experiencias Innovadoras en Educación Superior, Universidad de Buenos Aires. 2009.

LANGDON, E. J. “Performance e sua Diversidade como Paradigma Analítico: A Contribuição da Abordagem de Bauman e Briggs" Anais do Colóquio Antropologias em Performance Vânia Z. Cardoso Organizadora. GESTO/PPGAS/ NuPPe/UFSC Florianópolis. 2009. p. 252-271

MERTZ, E. Recontextualization as Socialization: Text and Pragmatics in the Law School Classroom. En Natural Histories of Discourse, Edited by Michael Silverstein and Greg Urban. Chicago and London: The University of Chicago Press. 1996. p. 229-249.

. Linguistic Ideology and Praxis in U.S. Law School Classrooms. En Language Ideologies. Practice and Theory. Edited by Bambi Schieffelin, Kathryn Woolard and Paul V. Kroskrity. New York Oxford: Oxford University Press. 1998. p. 149-162. 
Fernando Fischman

SINGER, M. When a Great Tradition Modernizes. Chicago: University of Chicago Press. 1972.

YANKAH, K. Speaking for the Chief. Okyeame and the Politics of Akan Royal Oratory. Bloomington and Indianapolis: Indiana University Press. 1995.

Recebido em: 10/06/2010

Aceite em: 20/07/2010

ILHA

volume 11 - número 1 